\title{
Erratum to: The representation of third person and its consequences for person-case effects
}

\author{
Andrew Nevins ${ }^{1}$
}

Published online: 5 July 2016

(C) Springer Science+Business Media Dordrecht 2016

\section{Erratum to: Nat Lang Linguist Theory (2007) 25:273-313 DOI 10.1007/s11049-006-9017-2}

This article has been published with the following errors: on page 278, three instances of '- singular' should be '+ + singular'; on page 307, two instances of the symbol $\cap$ should be the symbol $\cup$. These issues are corrected below and should be regarded as the final version by the reader.

At the same time, I would not like to wholly discount the role of phonological similarity in providing a diachronic nudge for the morphologization of (15), and for phonological factors quite generally to provide a force in the grammaticalization of a formal morphological constraint such as (15). For example, consider the fact that amn't is an impossible form in many dialects of British and North American English (Francis, 1985; Bresnan, 2001). This is arguably due to a synchronic filter banning the feature combination [+copula, +Pres, +neg, +Auth, +PSE, + singular] on a single syntactic node, which is resolved in various ways: in the dialect identified as " $\mathrm{Nb} 5$ " in Francis (1985) as isn't (i.e., via deletion of [+Auth, +PSE]), while in North American English as aren't (i.e. via deletion of [+singular]). On the other hand, the fact that amn't is tolerated in the dialect identified as "Nb 1" in Francis (1985), and is

The online version of the original article can be found under doi:10.1007/s11049-006-9017-2.

A. Nevins

a.nevins@ucl.ac.uk

1 Department of Linguistics, Harvard University, 317 Boylston Hall, Cambridge, MA 02139, UK 
even attested in children's speech (as revealed by a search conducted on CHILDES ${ }^{6}$ ) suggests that there is no active phonological constraint against this form in English; if there were, it should be rescuable in the phonology, e.g., by epenthesis of a vowel, or by deletion of one of the two coda nasals (cf. autumn $\sim$ autumnal). Rather, certain dialects have arguably morphologized a ban on the feature combination [+copula, + Pres, +neg, +Auth, +PSE, +singular] and respond to this morphosyntactic filter through various morphological repairs (e.g., feature deletion). While phonological pressures may play a role in shaping the diachronic development of purely morphological filters, the claim is that the synchronic representation of the ban on *amn't and the *le lo constraint is morphological in nature: a ban on morphological feature co-occurence.

The example (95) on page 307 should read:

(95) Interpretive possibilities for Impersonal pronouns:

$\{[+$ Participant, + Author $] \cup[+$ Participant, - Author $]$

$\cup[$-Participant, -Author $]\}$

${ }^{6}$ The following three examples were culled from a search of every child in the database. Notably, none of their parents uttered amn't in the database.

a. Mummy I'm doing all it by myself amn't I? [belfast/john07.cha:1435; age 4;4.1]

b. I'm doing this puzzle well amn't I? [macwhin/BOYS/boys67.cha:1464; age 3;11.18]

c. Amn’t I clever? [macwhin/BOYS/boys67.cha:2292; age 3;11.18] 